\title{
MINI-REVIEW
}

\section{Nutrition challenges in polytrauma patients. New trends in energy expenditure measurements}

\author{
Barbara Kołakowska ${ }^{1}$ \\ ${ }^{1}$ Faculty of Medicine, Medical University of Warsaw, Warsaw, Poland \\ Correspondence to: \\ Barbara Kołakowska \\ Faculty of Medicine, Medical University of Warsaw, Warsaw, Poland \\ E-mail: basia_kolakowska@op.pl
}

\section{Conflicts of interests}

Nothing to declare

\section{Acknowledgements}

None.

Funding: This research did not receive any specific grant from funding agencies in the public, commercial or not-for profit sectors.

Keywords: sepsis; nutrition; biomarkers; indirect calorimetry.

These authors take responsibility for all aspects of the reliability and freedom from bias of the data presented and their discussed interpretation.

Central Eur J Clin Res 2019;2(1):51-57

Received: 01.04.2019, Accepted: 10.04.2019, Published: 13.04.2019

Copyright $\odot 2018$ Central European Journal of Clinical Research. This is an open-access article distributed under the Creative Commons Attribution License, which permits unrestricted use, distribution, and reproduction in any medium, provided the original work is properly cited.

\section{Abstract}

Patients hospitalized in Intensive Care Units (ICU) are in severe general condition and they need specialized care, rehabilitation and proper nutrition to improve their condition and recover as soon as possible. Therefore, it is very important that nutrition consists of all necessary elements that will cover their daily demand for nutrients. However, malnutrition among ICU patients is very common. According to statistics, up to $50 \%$ is malnourished. It enhances average length of stay, risk of infection, prolongs ventilator days, delays wound healing and translates into an increased hospital cost. It may end in multi-organ failure, what in consequence increases mortality. Polytrauma pa- tients lost their energy because of intensified catabolism, due to neuroendocrine changes and inflammatory reactions, which may worsen already existing malnutrition.

\section{Background}

The goal of nutrition support therapy is to avoid catabolic response for critically ill patients, which causes several complications, weaken the metabolic response to shock, prevent the injuries caused by free oxygen radicals and favorably modulate the immune response (1-3) . At present, in clinical practice few methods find application and out of them the most beneficial seems to be early enteral nutrition (EN) $(4,5)$. It reduces disease severity, risk of infections, septic complications, modulates systemic immune response, maintains gut in- 
tegrity and has a favorable impact on patient's outcome. Some meta-analysis show that early enteral nutrition, provided within 24 hours of intensive care unit admission, significantly decreases mortality in critically ill patients. However, sometimes enteral nutrition is impossible or insufficient to provide appropriate demand on nutrients. In that case, parenteral nutrition (PN) should be included. Also, patients, who cannot tolerate $\mathrm{EN}$ or there are contraindications to use it, should receive the parenteral nutrition (PN), if they are not expected to be on normal nutrition within 3 or 4 days. It is recommended to use both methods at the same time, because using PN alone may cause hyperglycemia, hepatocellular injury and immunosuppression, which may be very harmful for patients in severe condition $(6-8)$.

\section{Metabolism during sepsis}

In sepsis, the recognition of foreign antigens leads to inflammatory response at the place of infection. The essence of these complex reactions is to produce pro-inflammatory factors like TNF- alfa, interleukin 1, interleukin 6 , interleukin 12, and interleukin 15 , which results in inflammatory cascade, leading to limitation and then destruction of the infectious place. Many factors, including organism's response and products made by pathogens, may be very adverse on the course of inflammatory reaction, which results in multi-organ failure or disseminated intravascular coagulation (DIC). Simultaneously, the anti-inflammatory processes with participation of cytokines like interleukin 4 , interleukin 10, interleukin 13 are taking places (911). Also the level of tumor growth factor beta (TGF-beta) and cortisol are increased. With advantage of anti-inflammatory factors, especially in polytrauma patients, may occur immunity impairment or deepening in severity of sepsis (8,12-15).

Sepsis-induced organ dysfunction has been suggested to be at least in part due to mitochondrial dysfunction. This condition is caused by oxidative stress (OS), which may result in failure of energy production. The pathogenesis of mitochondrial damage is recognized as a complex series of events. Both nitric oxide (NO) and oxigen free radicals (ROS) combined with the release of a variety of exacerbating inflammatory mediators can act to directly or indirectly influence mitochondrial function and energy production. It is hard to define whether the self-amplifying cycle of ROS generation and mitochondrial damage occurs with mitochondrial dysfunction leading to oxidative stress and more mitochondrial impairment as the primary event, or if oxidative stress initiates mitochondrial dys- function and then ROS are realesed (16-18). Improvement in mitochondrial respiration plays an important role, because it is suggested to be associated with the recovery of organ function in patients, who survive sepsis (13).

When patient is not fasted, but metabolic response develops due to sepsis etc., we are dealing with stress starvation. It leads to many changes which consist of increase of metabolism, acceleration of protein catabolism, increase of glucose circulation, exacerbation of sodium and water retention, reduction of albumin concentration in plasma and and increased secretion of catabolic hormones in combination of insulin resistance. The balance between elevated level of catabolic hormones and reduced function of insulin as well as an influence of anabolic hormones on metabolism of proteins, carbohydrates and fats is significantly changed. Due to this, the nutrition in patients with diagnosed sepsis should be well- balanced and including all necessary elements in appropriate doses. Choosing the right method of nutrition plays a significant role in patient's therapy. The biggest application has enteral nutrition (EN). It is well-tolerated way of feeding and it causes the least complications. It should be always the first choice for the clinictians starting nutrition in patients in severe condition, if there are no contrindiactions for that method like: (1) Diseases associated with ileus: multiple trauma with significant retroperitoneal hematoma and peritonitis; (2) Intestinal obstruction; (3) Active gastrointestinal hemorrhage; (4) Hemodynamic instability - it can worsen ischemia and may lead to necrosis and bacterial overgrowth. If these conditions occur, we must take parenteral nutrition under consideration. However, there are some situations in which we cannot use the PN. The contraindications are: (1) The possibility of gastrointestinal feeding, (2) Irreversibly decerebreate patients, (3) Lack of specific therapeutic goal, (4) Severe cardiovascular instability or metabolic derangements $(19,20)$. methods Energy Expenditure measurements

Considering estimation of energy expenditure (EE), there are 3 available options: direct calorimetry (DC), indirect calorimetry (IC) and predictive equations and formulas elaborated on basis of above measurements. Direct calorimetry is practically not used in clinical practice anymore, as requires special big and thermally isolated chambers (to put patient inside in order to capture and measure total body heat output) and is very burdensome for patients and physicians; cost of measurement is also very high. Indirect calorimetry is gaining more and more clinical confidence and usage and is strongly recommended (if only available) 
by all published guidelines with the most actual ESPEN (www.espen.org) guidelines on the top (21-23).

Traditional method for estimating energy expenditure (EE) is the use of predictive equations: they are easy to use, equation used differs by patient, clinical scenario, and clinician preference, but only $14-32 \%$ of patients receive accurate nutritional regimens. Over past 100 years, 200 different mathematic equations and formulas were elaborated and published, but currently, Harris-Benedict formula seems to be one of the most commonly used. This was developed by two physicians: Harris and Benedict in 1919 based on the results deriving from the group of 333 healthy patients (female, male and newborns), just after awakening, mentally and physically relaxed, 12-14 hours after last meal, stable ambient temperature, normal body temperature $(24,25)$. How these conditions correspond with seriously ill patient in ICU, which is usually sedated, getting NMBs, ventilated, under/overfeeded, having SIRS increasing oxygen demand, tissue perfusion failures, dysfunctional liver etc. These are main factors impacting negatively accuracy of EE estimation using predictive equations and making them inefficient and not recommended (Table 1).

\begin{tabular}{llll}
\hline Equation & Findings & Recommendation \\
\hline Fick Method & $\begin{array}{l}\text { Overestimate } \\
\text { Imprecise }\end{array}$ & Not recommended \\
\hline Harris-Benedict (HB) & without added factors & Underestimate & Not recommended \\
\hline HB with factors & $\begin{array}{l}\text { Under AND overestimate } \\
\text { Imprecise }\end{array}$ & Not recommended \\
\hline Swinamer & Inaccurate & Limited data - inconclusive \\
\hline Ireton-Jones (1992) & Inaccurate & Limited data - inconclusive \\
\hline Ireton-Jones (1997) & Inaccurate & Not recommended \\
\hline Penn State (2003) & Accurate in BMI <30 & $\begin{array}{l}\text { Recommended in BMI <30 } \\
\text { Inconclusive }\end{array}$ \\
\hline
\end{tabular}

Table 1. Factors impacting negatively accuracy of EE estimation using predictive equations

Bearing in mind all limitations and weaknesses of direct calorimetry and predictive equations in daily clinical practice and proper estimation of patient EE, indirect calorimetry is perceived as golden standard and highly recommended by all published guidelines (26). Instead of measuring the heat output of the body (like in direct calorimetry measurement) indirect calorimetry calculates the total Energy Expenditure (EE) and Respiratory Quotient (RQ) by measuring Respiratory Gas Exchange i.e. the consumption (or uptake) of $\mathrm{O} 2$ (VO2) and production (or elimination) of CO2 (VCO2) which are the result of oxidization (burning) of food and nutrients to generate energy for the human body. We know exactly what is the amount of consumed $\mathrm{O} 2$ and produced $\mathrm{CO} 2$ in process of metabolism of fats, carbohydrates and proteins; we also know, how much energy is released during metabolism of these substrates. Therefore, measuring $\mathrm{O} 2$ consumption and $\mathrm{CO} 2$ production, we are capable to estimate real energy expenditure. Indirect calorimetry measurement is continuous and non-invasive procedure, that can be applied for adult and pediatric patients (27-30).

Clinical indications for routine indirect calorimetry measurement are represented by:

- Multiple trauma;

- Neurological trauma;

- Burns;

- Multi-system organ failure;
- Sepsis;

- Systemic inflammatory response syndrome (SIRS);

- Acute respiratory distress syndrome (ARDS);

- Use of paralytic agents or sedation;

- Post-operative organ transplantation;

- Large or multiple open wounds;

- Malnutrition with altered body composition o Underweight;

o Obesity;

o Limb amputation;

o Peripheral edema;

o Ascites:

There are different devices for gas exchange and indirect calorimetry measurement available on the market, but one of the most commonly used is technology invented and delivered by GE Healthcare (GE Healthcare, Helsinki, Finland). Since 1975, when first compact capnometer was launched, through Deltatrac (1986), which is still positioned and perceived as golden standard and reference device for gas exchange measurement, to last versions of miniaturized respiratory gas modules that can be used in ventilators, cardiomonitors and even anesthesia units. GE Healthcare (GE Healthcare, Helsinki, Finland), is worldwide leader in gas exchange measurement and has delivered more 400000 modules to healthcare providers over last years (31-34).

Using GE technology and solutions (GE Healthcare, Helsinki, Finland), gas exchange 
measurement is very easy and non-invasive or time consuming; it doesn't require any special skills or knowledge and can be easily performed by each member of ICU staff. Following elements and accessories are needed to perform measurement:

- Gas module E-sCOVX (GE Healthcare, Helsinki, Finland), which is measuring $\mathrm{O} 2$ concentration via paramagnetic sensor and $\mathrm{CO}_{2}$ concentration via infrared sensor; gas module can be inserted either to GE Healthcare ventilator (GE Healthcare, Helsinki, Finland) or GE Healthcare cardiomonitor (GE Healthcare, Helsinki, Finland) (Figure 1).

- D-lite/Pedi-lite gas sampler and flow sensor

\section{Synchronization of gas and flow curves}

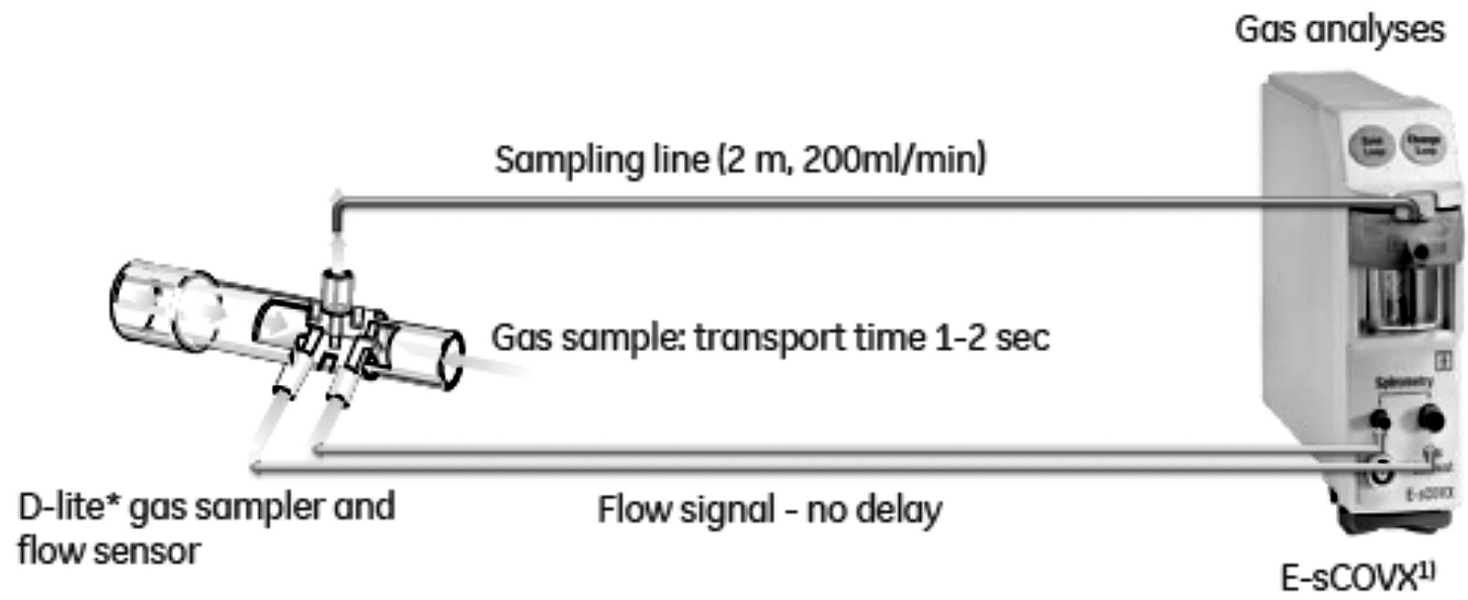

Figure 1. E-SCOVX gas sample module (GE Healthcare, Helsinki, Finland)

Following parameters are measured with indirect calorimetry:

- Respiratory quotient $(\mathrm{RQ})=\mathrm{VCO} 2 \mathrm{I}$ VO2, physiological range between 0,7 and 1,3 ,

- Energy expenditure (EE), Weir equation:

EE adult (kcal/day) $=5.5 x \mathrm{VO} 2(\mathrm{ml} / \mathrm{min})$ + 1.76x VCO2 (ml/min) - 1.99 x UN (g/day) EE ped $(\mathrm{kcal} /$ day $)=5.5 x \mathrm{VO} 2(\mathrm{ml} / \mathrm{min})$ $+1.76 x$ VCO2 (ml/min).

The fact that this method is indirect introduces several limitations which need to be well understood by the physician who will use the provided data as well as by the clinicians who will help generate such data. Every clinician using Indirect Calorimetry should understand and account for its limitations, before reporting and interpreting results.

The limitations of Indirect Calorimetry stem from both human physiology and the way Energy Expenditure (EE) and Respiratory Quotient $(R Q)$ are measured $(32,35,36)$.

\section{Leaks}

Indirect Calorimetry uses measured VO2 and VCO2 (minute volumes of consumed $\mathrm{O} 2$ and produced CO2) to calculate Energy Expenditure (EE) and Respiratory Quotient (RQ). In order to have a representative result the device must measure all the $\mathrm{O} 2$ consumed and all
$\mathrm{CO} 2$ produced. Any leaks

- in the ventilator circuit or

- around the artificial airway (endotracheal or tracheostomy tube)

- parenchymal leaks in the lung from fistulas, pneumothorax or chest drains etc.

will affect the measurement. For this reason, measuring a patient ventilated in NIV (noninvasive mode) via a mask or other NIV interface is not advisable. Leaks should be probed prior to IC measurements and eliminated as much as possible $(21,37)$.

\section{Blood filtration}

For the same reason as above, Indirect Calorimetry may provide inaccurate data during hemodialysis or peritoneal dialysis.

\section{N2O and other gas mixtures}

Indirect Calorimetry cannot be performed in the presence of N2O. Please note that the elimination of $\mathrm{N} 2 \mathrm{O}$ from the body and also from diffusion is not immediate and patients should not be measured during or immediately after anesthesia involving $\mathrm{N} 2 \mathrm{O}$.

In general, Indirect Calorimetry measurements should not be performed if there are any other gases apart from Air/O2 are present at the airway (38). 


\section{4. $\mathrm{FIO} 2>85 \%$}

VO2, which is one of the input variables in calculating Energy Expenditure and $R Q$, has a measurement accuracy which depends on $\mathrm{FiO} 2$. The higher the $\mathrm{FiO} 2$, the lower the $\mathrm{VO} 2$ accuracy. This is due to a mathematical calculation employed called Haldane transformation and it is not a reflection of changing inaccuracy of the oxygen and flow sensors. For most accurate results, $\mathrm{FiO} 2$ should be less than $65 \%$ (13).

\section{Conclusions}

The nutrition in ICU is an important factor, included in specialized therapy of polytrauma patients. The appropriate doses and content of nutrients can improve the general state of patient. The nutrition should be chosen, basing on the knowledge of processes, characteristic for the disease. Enteral nutrition is the most common method and should always be a first choice. Nowadays, the gold standard of estimation of demand and energy expenditure is indirect calorimetry. More guidelines recommend this method, because it is authoritative, non-invasive, easy to performed. In some countries the IC is refunded.

A pictorial example is an analysis, in which 5 women, with the same height and weight were considered. Basing on mathematic equations, predicted EE was almost equal. Using the IC, it was demonstrated that real energy expenditure (REE) was between over 1200 and almost 2300 (kcal/day). Taking into consideration all aspects, IC is seemed to be the best way to estimate the patient's real energy expenditure. It reduces the ICU length of stay, mechanical ventilation days and mortality.

\section{References}

1. Finfer S. Clinical controversies in the management of critically ill patients with severe sepsis. Virulence [Internet]. 2014;5(1):200_5. Available from: http://www.tandfonline. com/doi/abs/10.4161/viru.25855

2. Lee SH, Park MS, Park BH, Jung WJ, Lee IS, Kim SY, et al. Prognostic implications of serum lipid metabolism over time during sepsis. Biomed Res Int. 2015;2015(Ldl).

3. Simsek T, Uzelli Simsek H, Canturk NZ. Response to trauma and metabolic changes: posttraumatic metabolism. Turkish J Surg [Internet]. 2014;30(3):153-9. Available from: http://www.ulusalcerrahidergisi. org/eng/abstract/1137/eng

4. Novak F, Heyland DK, Avenell A, Drover JW, Su X. Glutamine supplementation in serious illness: A systematic review of the evidence*. Crit Care Med [Internet]. 2002;30(9). Available from: http://journals. Iww.com/ccmjournal/Fulltext/2002/09000/ Glutamine_supplementation_in_serious_ illness_A. A. 11.aspx

5. Mara J, Gentles E, Alfheeaid HA, Diamantidi K, Spenceley N, Davidson M, et al. An evaluation of enteral nutrition practices and nutritional provision in children during the entire length of stay in critical care. 2014;19.

6. Hu W, Cajas-monson LC, Eisenstein S, Parry L, Cosman B, Ramamoorthy S. Preoperative malnutrition assessments as predictors of postoperative mortality and morbidity in colorectal cancer : an analysis of ACS-NSQIP. 2015;1-6.

7. Id AS, Theilla M, Hellerman $M$, Singer $P$, Maggiore $U$, Barbagallo $M$, et al. Energy and Protein in Critically III Patients with AKI : A Prospective, Multicenter Observational Study Using Indirect Calorimetry and Protein Catabolic Rate.

8. Pravda J. Metabolic theory of septic shock. World J Crit Care Med [Internet]. 2014;3(2):45-54. Available from: http:// www.pubmedcentral.nih.gov/articlerender. fcgi? artid=4038812\&tool=pmcentrez\&rendertype=abstract

9. Dogjani A, Zatriqi S, Uranues S, Latifi R. Biology-based nutritional support of critically ill and injured patients. Eur Surg - Acta Chir Austriaca. 2011;43(1):7-12.

10. Ostrowski SR, Sørensen AM, Windeløv NA, Perner A, Welling K-L, Wanscher M, et al. High levels of soluble VEGF receptor 1 early after trauma are associated with shock, sympathoadrenal activation, glycocalyx degradation and inflammation in severely injured patients: a prospective study. Scand J Trauma Resusc Emerg Med [Internet]. 2012;20(1):27. Available from: http://sjtrem.biomedcentral.com/articles/10.1186/1757-7241-20-27

11. Davis SM, Clark EAS, Nelson LT, Silver RM. The association of innate immune response gene polymorphisms and puerperal group A streptococcal sepsis. Am J Obstet Gynecol [Internet]. 2010 Mar;202(3):308. e1-308.e8. Available from: http://www. sciencedirect.com/science/article/pii/ S0002937810000074

12. de Oliveira Iglesias $S$, Leite $H$, Paes $\hat{A}$, de Oliveira S, Sarni R. Low plasma selenium concentrations in critically ill children: the interaction effect between inflammation and selenium deficiency. Crit Care [Internet]. 2014;18(3):R101. Available from: http://ccforum.biomedcentral.com/articles/10.1186/cc13877

13. Rogobete AF, Sandesc D, Papurica M, 
Stoicescu ER, Popovici SE, Bratu LM, et al. The influence of metabolic imbalances and oxidative stress on the outcome of critically ill polytrauma patients: a review. Burn Trauma [Internet]. 2017;5(1):8. Available from: http://burnstrauma.biomedcentral.com/articles/10.1186/s41038-017-0073-0

14. Hartl WH, Jauch KW. Metabolic self-destruction in critically ill patients: Origins, mechanisms and therapeutic principles. Nutrition [Internet]. 2014;30(3):261-7. Available from: http://dx.doi.org/10.1016/j. nut.2013.07.019

15. Andrews PJD, Avenell A, Noble DW, Campbell MK, Croal BL, Simpson WG, et al. Randomised trial of glutamine, selenium, or both, to supplement parenteral nutrition for critically ill patients. Bmj [Internet]. 2011;342(mar17 2):d1542-d1542. Available from: http://www.bmj.com/cgi/ doi/10.1136/bmj.d1542

16. Papurica $M$, Rogobete $A F$, Sandesc $D$, Dumache R, Nartita R, Sarandan M, et al. Redox Changes Induced by General Anesthesia in Critically III Patients with Multiple Traumas. Mol Biol Int. 2015;2015:238586.

17. Bedreag $\mathrm{OH}$, Rogobete AF, Sandesc D, Cradigati CA, Sarandan M, Popovici SE, et al. Modulation of the Redox Expression and Inflammation Response in the Critically III Polytrauma Patient with Thoracic Injury. Statistical Correlations between Antioxidant Therapy and Clinical Aspects A Retrospective Single Center Study. 2016;(10):1747-59.

18. Papurica M, Rogobete AF, Sandesc D, Dumache R, Cradigati CA, Sarandan M, et al. Advances in biomarkers in critical ill polytrauma patients. Clin Lab. 2016;62(6).

19. Bedreag $\mathrm{OH}$, Rogobete $A F$, Sărăndan $M$, Cradigati $A$, Păpurică $M$, Maria $O$, et al. Oxidative stress and antioxidant therapy in traumatic spinal cord injuries. 2014;21(2):123-9.

20. Koekkoek WAC (Kristine), van Zanten ARH. Antioxidant Vitamins and Trace Elements in Critical Illness. Nutr Clin Pract [Internet]. 2016;31(4):457-74. Available from: http://journals.sagepub.com/ doi/10.1177/0884533616653832

21. Maraki MI, Panagiotakos B, Jansen LT. Validity of Predictive Equations for Resting Energy Expenditure in Greek Adults. 2018;72701:134-41.

22. Nakajima $\mathrm{N}$, Ito $\mathrm{Y}$, Yokoyama $\mathrm{K}$, Uno $\mathrm{A}$, Kato K, Iwasaki A, et al. The expresssion of Mdm2 on Helicobacter pylori infected intestinal metaplasia and gastric cancer. J Clin Biochem Nutr. 2005;128(4):A401-2.

23. Compher C, Frankenfield D, Keim N, Roth-Yousey L. Best Practice Methods to
Apply to Measurement of Resting Metabolic Rate in Adults: A Systematic Review. J Am Diet Assoc. 2006;106(6):881-903.

24. Frankenfield D, Hise M, Malone A, Russell M, Gradwell E, Compher C. Prediction of resting metabolic rate in critically ill adult patients: results of a systematic review of the evidence. J Am Diet Assoc. 2007;107(9):1552-61.

25. Kross EK, Sena M, Schmidt K, Stapleton $\mathrm{RD}$. A comparison of predictive equations of energy expenditure and measured energy expenditure in critically ill patients. J Crit Care [Internet]. 2012;27(3):321. e5-321.e12. Available from: http://dx.doi. org/10.1016/j.jcrc.2011.07.084

26. In R, Eh E. Recent advances in gas exchange measurement in intensive care patients. 2003;91(1):120-31.

27. Hensel M, Kox WJ. Increased intrapulmonary oxygen consumption in mechanically ventilated patients with pneumonia. Am J Respir Crit Care Med [Internet]. 1999;160(1):137-43. Available from: http:// www.ncbi.nlm.nih.gov/pubmed/10390391

28. Moral V. Alveolar recruitment improves ventilation during thoracic surgery : a randomized controlled trial. 2012;108(May 2011):517-24.

29. Peyton P, Stuart-andrews C, Robinson G. Indirect Calorimetry has Better Reproducibility than the Reverse Fick Method in Measurement of Oxygen Uptake. 2010;16.

30. Singer P, Pogrebetsky I, Attal-Singer J, Cohen J. Comparison of metabolic monitors in critically ill, ventilated patients. Nutrition. 2006;22(11-12):1077-86.

31. Briassoulis G, Michaeloudi E, Fitrolaki DM, Spanaki AM, Briassouli E. Influence of different ventilator modes on Vo2 and Vco2 measurements using a compact metabolic monitor. Nutrition [Internet]. 2009;25(1112):1106-14. Available from: http://dx.doi. org/10.1016/j.nut.2009.01.018

32. Meyer R, Briassouli E, Briassoulis G, Habibi P. Evaluation of the M-COVX metabolic monitor in mechanically ventilated adult patients. e-SPEN. 2008;3(5).

33. Sundström M, Tjäder I, Rooyackers $O$, Wernerman J. Indirect calorimetry in mechanically ventilated patients. A systematic comparison of three instruments. Clin Nutr [Internet]. 2013;32(1):118-21. Available from: http://dx.doi.org/10.1016/j. clnu.2012.06.004

34. Blond E, Maitrepierre C, Normand S, Sothier M, Roth $\mathrm{H}$, Goudable J, et al. A new indirect calorimeter is accurate and reliable for measuring basal energy expenditure, thermic effect of food and substrate 
oxidation in obese and healthy subjects. e-SPEN [Internet]. 2011;6(1):e7-15. Available from: http://dx.doi.org/10.1016/j.ecl$\mathrm{nm} .2010 .12 .001$

35. Graf S, Karsegard VL, Viatte V, Heidegger CP, Fleury Y, Pichard C, et al. Evaluation of three indirect calorimetry devices in mechanically ventilated patients: Which device compares best with the Deltatrac $\| \circledast$ ? A prospective observational study. Clin Nutr [Internet]. 2015;34(1):60-5. Available from: http://dx.doi.org/10.1016/j. clnu.2014.01.008

36. Wang X, Ms YW, Ding Z, Ms GC, Hu F. Relative validity of an indirect calorimetry device for measuring resting energy expenditure and respiratory quotient. 2018;27(December 2015):72-7.

37. Rosado EL, Kaippert VC, Brito RS De. Energy Expenditure Measured by Indirect Calorimetry in Obesity. 2013;

38. Panitchote A, Thiangpak N, Hongsprabhas $P$, Hurst C. Short Communication Energy expenditure in severe sepsis or septic shock in a Thai Medical Intensive Care Unit. 2017;26(April 2016):794-7. 